Published in final edited form as:

Semin Hematol. 2007 April ; 44(2): 62-69.

\title{
Epidemiology and Risk Factors for Venous Thrombosis
}

\author{
Mary Cushman, MD, MSc \\ Associate Professor of Medicine and Pathology, Director, Thrombosis and Hemostasis Program, \\ University of Vermont College of Medicine and Fletcher Allen Health Care, Burlington, Vermont
}

\begin{abstract}
Venous thrombosis, including deep vein thrombosis and pulmonary embolism, occurs at an annual incidence of about 1 per 1000 adults. Rates increase sharply after around age 45 years, and are slightly higher in men than women in older age. Major risk factors for thrombosis, other than age, include exogenous factors such as surgery, hospitalization, immobility, trauma, pregnancy and the puerperium and hormone use, and endogenous factors such as cancer, obesity, and inherited and acquired disorders of hypercoagulation. This review focuses on epidemiology of venous thrombosis and the general implications of this in patient management.
\end{abstract}

Venous thrombosis, comprising deep vein thrombosis (DVT) and pulmonary embolism (PE), occurs with an incidence of approximately 1 per 1000 annually in adult populations (1). Rates are slightly higher in men than women. About two-thirds of episodes manifest as DVT and one-third as PE with or without DVT. The major outcomes of venous thrombosis are death, recurrence, post-thrombotic syndrome and major bleeding due to anticoagulation. Thrombosis is also associated with impaired quality of life, particularly when post-thrombotic syndrome develops $(2,3)$. Death occurs within one month of an episode in about $6 \%$ of those with DVT and $10 \%$ of those with PE (4). The mortality rate for PE has been estimated to be high as $30 \%$ in studies that included autopsy-based PE diagnosis (5), pointing out the fact that many PE are not recognized clinically before death. Mortality rates are lower among patients with idiopathic venous thrombosis and highest among those whose thrombosis occurs in the setting of cancer.

Venous thrombosis is a disease of aging, with a low rate of about 1 per 10,000 annually before the fourth decade of life, rising rapidly after age 45 years, and approaching 5-6 per 1000 annually by age 80 (6). In one study the 8 -year rate among those 85 and older at baseline was 13 -fold greater than in those aged 45-55, with an absolute rate of 7 per 1000 annually (7). The morbidity impact of thrombosis on the elderly appears to be greater, with a steeper rise in incidence of PE as compared to DVT with aging (6). Thus, a higher case fatality of thrombosis in older persons is seen. It is likely that thrombosis is less diagnosed in certain debilitated elderly patients so these estimates are probably underestimates. The reasons for an increased thrombosis risk with age are not understood, but may relate to increasing presence of other illnesses predisposing to thrombosis, to increases in coagulation potential, or some combination of these.

There are also differences in incidence of diagnosed venous thrombosis among ethnic groups with rates lower, in the United States, in Asians, Pacific Islanders and Hispanics than in whites $(8,9)$, and with some studies reporting an approximate $25 \%$ higher rate in African-Americans

Correspondence: Mary Cushman, MD, MSc, Department of Medicine, University of Vermont, 208 South Park Drive, Suite 2, Colchester, VT 05446. phone: 802-656-8968; fax: 802-656-8965; email: mary.cushman@uvm.edu

Publisher's Disclaimer: This is a PDF file of an unedited manuscript that has been accepted for publication. As a service to our customers we are providing this early version of the manuscript. The manuscript will undergo copyediting, typesetting, and review of the resulting proof before it is published in its final citable form. Please note that during the production process errors may be discovered which could affect the content, and all legal disclaimers that apply to the journal pertain. 
$(7,8)$. In one study this increased risk in blacks was greater for secondary than idiopathic VTE, suggesting possible differences in use or efficacy of prophylaxis (7). There is little information on epidemiology of thrombosis in Africa. Two recent reports suggested that rates of hospitaltriggered DVT or postoperative DVT were similar in Asian and in Western countries $(10,11)$, although the population rate of DVT in China has been estimated at only 0.17 per 1000 annually (12). The findings of the former two studies might be explained by an increased frequency of asymptomatic episodes detected by screening, and further work is needed to determine the clinical significance. Observed ethnic differences in thrombosis incidence might be related to a lower prevalence of disorders like factor V Leiden or the prothrombin 20210A mutation in non-Caucasians (13-17). Although factor V Leiden is relatively rare in African-Americans (18), it confers a similarly increased risk of thrombosis (19). The fact that African-Americans report a similar prevalence of a family history of thrombosis to that of whites (20), and their possibly higher thrombosis risk than whites, suggests that unidentified gene variants play an important role in thrombosis in blacks. It was recently demonstrated that blacks have higher levels of several hemostatic markers of thrombosis risk, including factor VIII, von Willebrand factor and D-dimer, compared to whites (21). In this study, Chinese participants had lower levels of these factors. Reasons for these ethnic differences remain to be determined.

An understanding of the risk factors for venous thrombosis is necessary in order to maximize the prevention of this disease in high risk individuals and groups of patients. The major risk factors for thrombosis are listed in table 1 and include endogenous patient characteristics such as obesity and genetic factors, and triggering factors such as surgery, immobility or pregnancy. Some of the risk factors are modifiable, while others, like advancing age and genetic predispositions, are not. As illustrated in Fig 1, venous thrombosis tends to occur due to the additive effects of endogenous, genetic and environmental risk factors present simultaneously (22). This includes the additive effects of environmental risk factors; one general population study that followed 21,680 persons for occurrence of venous thrombosis over 7.6 years demonstrated that about one-half of all thrombosis events were considered secondary to triggering factors and, among these, $65 \%$ of the time more than one triggering risk factor was present (4). The most common factors were hospitalization in 52\%, cancer in $48 \%$ and surgery in $42 \%$. Trauma was only present in $6 \%$, revealing a relatively low potential number of cases globally that could be avoided with prophylaxis in this setting. This is probably due to the rarity of trauma compared to the other triggers. These findings, and those of others, point out the tremendous potential that thromboprophylaxis might have if it were effective and administered optimally in patients at risk of venous thrombosis (23). For example, if thromboprophylaxis were perfectly effective among hospitalized patients, up to $25 \%$ of all venous thromboembolisms could be avoided.

\section{Modifiable Risk Factors}

\section{Obesity}

An important modifiable risk factor for thrombosis is obesity. Obesity is defined as a bodymass index (BMI) above $30 \mathrm{~kg} / \mathrm{M}^{2}$. Internet sites are available for easy calculation of BMI in clinical settings or by patients (http://www.nhlbisupport.com/bmi). Obesity leads to a 2 to 3 fold higher risk of venous thrombosis in men and women (7,24-26). The risk associated with severe obesity (BMI above $40 \mathrm{~kg} / \mathrm{M}^{2}$ ) is even higher. In one study, the relationship of obesity to thrombosis risk was not mediated by differences in levels of fibrinogen, factor VIII, factor IX and D-dimer (25). Further work is needed to define the mechanism. It is possible that physical aspects of body size are important, leading to impaired venous return, and that biochemical parameters associated with obesity, such as increased coagulation and inflammation play a role. 
The obese have a further increase in thrombosis risk when they are exposed to other thrombosis risk factors, such as exogenous contraceptive or postmenopausal hormones $(25,27)$. One study estimated that the absolute risk of thrombosis for five years of estrogen plus progestin use in women aged 50-59 years with obesity was $1.5 \%$, compared to $0.5 \%$ in normal weight women (27). This highlights the importance of considering absolute risks associated with risk factors and their combinations; the relative risk of each factor, age, hormones and obesity is about 2fold, but to add clinical context, absolute risk assessment is needed.

The association of obesity with thrombosis is especially important because obesity is increasing dramatically worldwide. Between 1991 and 2004 obesity has more than doubled in the United States, with an estimated prevalence as high as $30 \%$ in some geographical areas. Rates of abdominal obesity are even higher (28). To illustrate the impact of this epidemic on expected rates of thrombosis, we used data from the United States Census and the Centers for Disease Control and Prevention to estimate the number of thrombosis cases that could be attributed to obesity from 1990 to 2000 . We estimate that in 1990 there were 18,500 cases of venous thromboembolism among obese people aged 45-64 years (based on the number of people in that age range, a prevalence of obesity of $10 \%$ at that time, and the expected rate of thrombosis in obesity compared to a normal weight). However, in 2000, we estimate that with a $25 \%$ prevalence of obesity, there were 62,000 cases of thrombosis among obese persons aged 4564. If the prevalence of obesity had remained $10 \%$ in 2000 , only 24,000 cases of thrombosis would have been expected in obese persons in this age group in that year. Thus, in 2000, there were 38,000 excess thrombosis cases among people aged 45-64 solely due to the rise in obesity.

\section{Homocysteine}

Elevated homocysteine has been consistently reported as a risk factor for venous thrombosis and levels can be reduced with B vitamin supplementation (44). Confirmation of the causal nature of this association requires randomized controlled trials of homocysteine lowering. The only completed trial among venous thrombosis patients did not show any benefit in prevention of recurrent events using $5 \mathrm{mg}$ folic acid, $50 \mathrm{mg}$ pyridoxine, and $0.4 \mathrm{mg}$ cyanocobalamin, compared with placebo, administered daily in 701 patients with previous idiopathic venous thrombosis (45). About one-half of participants in this study had hyperhomocysteinemia, so results can be considered fairly conclusive in refuting the homocysteine hypothesis. The role of homocysteine testing therefore seems limited.

\section{Temporary Risk Factors}

These conditions increase the risk of thrombosis, usually for a number of weeks following exposure. As described above, when more than one triggering condition or risk factor is present, the risk is usually higher. For example, if a patient were hospitalized for pneumonia and also had recent leg trauma, the risk of thrombosis would be higher in general than in a patient without recent trauma (29).

\section{Hospitalization}

Most hospitalized patients have risk factors for venous thrombosis, such as immobility, cancer, infection and surgery. Up to $20 \%$ of patients admitted to a medical service will have thrombosis and up to $40 \%$ admitted to a surgical service. Many of these events are not clinically apparent, but still could lead to later problems like pulmonary embolism. About $10 \%$ of all deaths in hospital are related to pulmonary embolism, and many times it was not suspected before death (30). For this reason it is important that most patients admitted receive prophylaxis against venous thromboembolism (31). 


\section{Surgery/Trauma}

The risk of thrombosis with surgery varies depending on the surgery type and patient characteristics. Curiously, one study reported that older patients did not have a higher risk of post-operative venous thrombosis than younger patients for certain types of surgery (32).

Preventive therapies against thrombosis are used, with the intensity of intervention relating to the risk status of the patient. Detailed discussion is beyond the scope of this paper but the periodically published guideline statement of the American College of Chest Physicians is a useful resource for more detail (31).

\section{Immobility}

Immobility increases the risk of thrombosis, presumably due to stasis of blood flow in the venous system. Relevant settings of immobility include bedrest, plaster casts on the legs and paresis of the legs due to neurological conditions. Research-based definitions of immobility due to bedrest differ, but a duration of 4 days seems reasonable. Minor forms of immobility, such as after minor surgery or injury, have also been linked to thrombosis risk (33).

\section{Cancer}

Cancer patients have an increased risk of thrombosis due to a combination of factors, as recently reviewed (34). Tumor cells activate coagulation, tumors can compress veins causing stasis and cancer patients are exposed to hospitalization, surgery and chemotherapy, which all increase their risk. In a recent cohort study including 66,329 patients with cancer, the incidence of venous thrombosis during the first 6 months after cancer diagnosis was 12.4 per 1000 (35). This would be equivalent to an annual rate of 24.6 per 1000, markedly higher than the average population risk. Metastatic disease and chemotherapy use further doubled the risk. Hormonal therapies increased the risk by $50 \%$ among breast cancer patients, but not among prostate cancer patients. Cancers involving the bone, ovary, brain, pancreas and lymphomas were associated with the highest incidence of thrombosis within 6 months of cancer diagnosis: 37.2, 32.6, 32.1, 22.7 and 17-20 per 1000, respectively. Including all the time from cancer diagnosis, cancers of the bone, ovary, uterus, Hodgkin's lymphoma, breast and brain had the highest incidence: $56.6,45.0,38.4,36.0,35.1,32.1$ per 1000 patients, respectively. Cancers of the ovary, pancreas, lung, stomach, and hematological malignancies had a high incidence of venous thromboembolism in the year before the cancer diagnosis, pointing out the possible role of occult cancer in causing thrombosis or a commonality of risk factors for both diseases (35). Available data suggest that cancer patients with factor V Leiden or prothrombin 20210A have a higher risk of cancer-related thrombosis than those without these disorders $(36,37)$.

The high absolute rate of thrombosis in cancer patients suggests that anticoagulant prophylaxis would be beneficial, particularly in high-risk situations like surgery. The benefit of long-term anticoagulation to prevent thrombosis in cancer patients requires confirmation in randomized controlled trials, especially since the risk of bleeding in anticoagulated cancer patients is high.

Travel

Any type of travel has the potential to increase the risk of venous thromboembolism; duration of travel is a key factor. Travel by air, car, train or bus for 4 or more hours all increase the risk by about 2-fold for several weeks after travel (38). As before, the risk is higher when other thrombosis risk factors are present. Data on absolute rates of thrombosis with air travel are limited but include 1.5 per million for severe pulmonary embolism among those traveling more than 3000 miles (39), and 0.39 per million for all pulmonary embolism (40). 


\section{Non-Modifiable Risk Factors}

\section{Genetic Factors}

Over the past 20 years several gene variants have been identified as risk factors for venous thrombosis. These conditions are often referred to as "thrombophilic disorders," "thrombophilias" or "hypercoagulable syndromes". Most of these have been defined in Caucasian populations and they are less frequent in other ethnicities. The relative risks of first venous thrombosis for many of these disorders based on two large studies are shown in table 2 . The Leiden Thrombophilia Study is a case control study of subjects $<70$ years without cancer, including 474 cases with a first DVT and 474 controls. Hemostatic factors were measured after thrombosis. The Longitudinal Investigation of Thromboembolism Etiology is a cohort study of 21,680 men and women aged 45-100 years followed over time for occurrence of venous thrombosis. Hemostatic factors were measured before thrombosis (4). In general, comparing the two studies, the strength of associations of thrombophilic risk factors with thrombosis risk was similar.

Thrombophilic disorders can be divided into loss-of-coagulation function disorders and gainof-coagulation function disorders (41). Loss-of-function disorders include deficiencies of the endogenous anticoagulants, antithrombin, protein $\mathrm{C}$ and protein $\mathrm{S}$. They are less common than gain-of-function disorders but may be more potent risk factors for thrombosis. Gain-offunction disorders include factor V Leiden, the prothrombin 20210A variant, and possibly elevation of procoagulant factors such as factor VIII, von Willebrand factor, and factors V, VII, IX and XI. These appear to be weaker risk factors for venous thromboembolism in general. The role of genetic variation in explaining associations of higher levels of factors VIII, IX and $\mathrm{XI}$ with venous thrombosis is uncertain.

Higher D-dimer is also a risk factor for first venous thrombosis in otherwise healthy individuals $(42,43)$. The relative risk of thrombosis with D-dimer in the top quarter of the normal population distribution was increased 2.5 to 3 -fold, and the risk was even higher for idiopathic thrombosis (43). This association can probably be explained by the impact of combinations of known and unknown hemostatic and environmental factors contributing to the level of D-dimer, since adjustment for known coagulation disorders partly confounds the association of D-dimer with thrombosis risk (43). Whether D-dimer evaluation would be useful in clinical settings for prevention of first episodes of venous thrombosis is unknown.

\section{Potential New Risk Factors}

Recently reported findings suggest other risk factors that require further study in order to confirm their importance.

Recent work has assessed physical activity level in relation to thrombosis risk. In the Longitudinal Investigation of Thromboembolism Etiology study of 21,690 men and women aged 45-100 at baseline, there was no association of baseline leisure time physical activity level with risk of future venous thrombosis (7). However, in the Multiple Environmental and Genetic Assessment (MEGA) case-control study including men and women aged 18-70, moderate exercise was associated with a lower risk of deep vein thrombosis of the arm (46). Some authors have suggested that prolonged sitting is a risk factor for deep vein thrombosis (47), but further research is needed on this topic.

Steffen and colleagues reported data from the Atherosclerosis Risks in Communities study regarding dietary factors and risk of thrombosis over 12 years (48). Among 14,962 participants, consuming $\geq 4$ fruit and vegetable servings daily and eating fish once weekly or more were 
both associated with a lower incidence of future venous thrombosis. Those consuming $>1.5$ servings of red and processed meat daily had a higher incidence.

An association of atherosclerosis with risk of venous thrombosis was suggested by Prandoni and colleagues who reported a higher frequency of carotid atherosclerotic plaques among patients with previous idiopathic venous thrombosis (49). These findings were not confirmed in the prospective LITE study, which measured subclinical atherosclerosis before occurrence of venous thrombosis and reported an inverse association or no association of various measures of atherosclerosis with future venous thrombosis $(50,51)$.

Some, but not all studies report higher thrombosis rates in the winter months $(1,52)$.

\section{Interaction of Genes and Environment in Thrombosis}

As discussed above, venous thrombosis often occurs when multiple risk factors, including genetic and environmental, are present at the same time. A classic illustration of this point is the interaction of oral contraceptive use and factor V Leiden. It is estimated that women heterozygous for factor V Leiden have a 3- to 7-fold increased risk of venous thromboembolism. Oral contraceptives confer a 2-3-fold increase in risk. In the presence of both risk factors, the relative risk is 34 -fold increased (53). This is probably because oral contraceptives induce activated protein $\mathrm{C}$ resistance, making the biochemical defect associated with factor V Leiden worse (54). The absolute rate of thrombosis then for unselected women with factor V Leiden in their 20's taking contraceptives is approximately 34 per 10,000 annually, so screening prior to oral contraceptive use would not be effective. This rate may be higher when there is a family history of thrombosis.

\section{Outcomes of Thrombosis}

\section{Recurrent Thrombosis}

Venous thrombosis is often a chronic condition, with recurrence rates estimated at 5-7\% annually after a first episode $(4,55,56)$. The risk is highest among those whose initial episode was associated with cancer, and lowest among those whose initial episode was associated with a temporary risk factor such as surgery $(4,55,56)$. In one study, older age and obesity were associated with higher recurrence risks (56). Recent reports suggest an approximate $60 \%$ higher recurrence risk among men compared to women (57). One study suggested that this increase in risk could be explained by a lower recurrence risk among women who were using exogenous hormones at the time of their first event (58). The risk appears to be highest in the 6-12 months following cessation of anticoagulation, regardless of the initial duration of anticoagulation (59).

Other risk factors for recurrent thrombosis include residual vein thrombosis on ultrasound, pulmonary embolism as the first thrombosis event, and proximal versus distal limb deep vein thrombosis. Hron et al were not able to demonstrate an association between a positive family history of thrombosis with risk of recurrent thrombosis among 829 patients without deficiencies of protein $\mathrm{C}$, protein $\mathrm{S}$ or antithrombin (60).

Use of testing for thrombophilic disorders has become widespread because these disorders are associated with risk of first thrombosis events. Subjects considered for this testing include those with thrombosis and their thrombosis-free family members. For testing to be considered clinically useful for a patient with thrombosis, it would be desirable if the testing helped identify a treatment strategy to prevent recurrent thrombosis. Whether these tests provide information that is useful for clinical management in decision-making about use of long-term anticoagulation is not yet clear (61-67). Most authors suggest that the presence of deficiencies 
of protein $\mathrm{C}$, protein $\mathrm{S}$ or antithrombin are relevant in this regard and that patients will have a nearly 2-fold higher recurrence risk. Recent reports suggest that some tests of overall clotting activity, such as D-dimer, peak thrombin generation or even the activated partial thromboplastin time, might be more useful in guiding clinical decision-making than more expensive tests for specific clotting disorders (67-72). For example, in two recent studies of long-term anticoagulation after an episode of venous thrombosis, higher D-dimer assessed after completion of an initial course of anticoagulation was associated with an increased risk of recurrent thrombosis, and this risk was lowered in those maintained on long-term anticoagulation (Fig 3) (67,70). Optimal testing strategies require further research.

\title{
Post-thrombotic Syndrome
}

Post-thrombotic syndrome occurs in 20-50\% of patients after a first DVT $(55,73)$. Symptoms include swelling, pain and skin problems ranging from dryness to discoloration and venous ulcers. Research has been hampered by the lack of validated diagnostic and scoring symptoms for severity (74). Risk factors for post-thrombotic syndrome are poorly understood. Older age, male sex, presence of proximal as compared to distal DVT and higher D-dimer have been suggested as risk factors $(55,75)$. In one study (76), but not another (75), there was a lower rate of post-thrombotic syndrome among those with factor V Leiden or the prothrombin 202010A mutation. Use of elastic compression stockings has been reported to be effective in prevention of post-thrombotic syndrome in those with DVT $(77,78)$, but no placebo-controlled trials are available.

\section{Family Testing}

The role of testing family members of patients with thrombosis and an identified thrombophilia is not clear (21). It might be expected that the knowledge of a risk factor would reduce the likelihood of future thrombosis in affected family members, but this remains to be proven. Important considerations in testing for genetic thrombophilia were reviewed recently (79).

\section{Conclusions}

An improved understanding of the epidemiology and risk factors for first and recurrent venous thrombosis can translate to improved clinical outcomes in practice. Consideration of risk factors can allow optimal use of prophylactic strategies against venous thrombosis.

\author{
Acknowledgements \\ Funded in part by R01 HL59367 from the National Heart, Lung, and Blood Institute; National Institutes of Health, \\ USA.

\section{References} \\ 1. White RH. The epidemiology of venous thromboembolism. Circulation 2003;107:I-4-I-8. [PubMed: \\ 12814979] \\ 2. van Korlaar IM, Vossen CY, Rosendaal FR, Bovill EG, Cushman M, Naud S, et al. The impact of \\ venous thrombosis on quality of life. Thromb Res 2004;114:11-18. [PubMed: 15262479] \\ 3. Kahn SR, Ducruet T, Lamping DL, Arsenault L, Miron MJ, Roussin A, et al. Prospective evaluation \\ of health-related quality of life in patients with deep venous thrombosis. Arch Intern Med \\ 2005;165:1173-1178. [PubMed: 15911732] \\ 4. Cushman M, Tsai AW, White RH, Heckbert SR, Rosamond WD, Enright P, et al. Deep vein thrombosis \\ and pulmonary embolism in two cohorts: the Longitudinal Investigation of Thromboembolism \\ Etiology. Am J Med 2004;117:19-25. [PubMed: 15210384]
}


5. Heit JA, Silverstein MD, Mohr DN, Petterson TM, O'Fallon WM, Melton LJ. Predictors of survival after deep vein thrombosis and pulmonary embolism: a population-based cohort study. Arch Intern Med 1999;159:445-453. [PubMed: 10074952]

6. Silverstein M, Heit J, Mohr D, Petterson T, O'Fallon W, Melton L. Trends in the incidence of deep vein thrombosis and pulmonary embolism: a 25-year population-based study. Arch Intern Med 1998;158:585-593. [PubMed: 9521222]

7. Tsai AW, Cushman M, Rosamond WD, Heckbert SR, Polak JF, Folsom AR. Cardiovascular risk factors and venous thromboembolism incidence: the Longitudinal Investigation of Thromboembolism Etiology. Arch Intern Med 2002;162:1182-1189. [PubMed: 12020191]

8. White R, Zhou H, Romano P. Incidence of idiopathic deep venous thrombosis and secondary thromboembolism among ethnic groups in California. Ann Intern Med 1998;128:737-740. [PubMed: 9556467]

9. Stein PD, Kayali F, Olson RE, Milford CE. Pulmonary thromboembolism in Asians/Pacific Islanders in the United States: analysis of data from the National Hospital Discharge Survey and the United States Bureau of the Census. Am J Med 2004;116:435-442. [PubMed: 15047032]

10. Piovella F, Wang CJ, Lu H, Lee K, Lee LH, Lee WC, et al. Deep-vein thrombosis rates after major orthopedic surgery in Asia. An epidemiological study based on postoperative screening with centrally adjudicated bilateral venography. J Thromb Haemost 2005;3:2664-2670. [PubMed: 16359505]

11. Leung V, Lui W, Chan T, Wong RS, Cheng G. Incidence of deep vein thrombosis in hospitalized Chinese medical patients is similar to that in western populations. Thromb Res 2006;118:763-764. [PubMed: 16460786]

12. Cheuk BL, Cheung GC, Cheng SW. Epidemiology of venous thromboembolism in a Chinese population. Br J Surg 2004;91:424-428. [PubMed: 15048741]

13. Gregg JP, Yamane AJ, Grody WW. Prevalence of the factor V-Leiden mutation in four distinct American ethnic populations. Am J Med Genet 1997;73:334-336. [PubMed: 9415695]

14. Ridker PM, Miletich JP, Hennekens CH, Buring JE. Ethnic distribution of factor V Leiden in 4047 men and women: implications for venous thromboembolism screening. JAMA 1998;277:1305-1307. [PubMed: 9109469]

15. Folsom AR, Cushman M, Tsai MY, Aleksic N, Heckbert SR, Boland LL, et al. A prospective study of venous thromboembolism in relation to factor V Leiden and related factors. Blood 2002;99:27202725. [PubMed: 11929758]

16. Folsom AR, Cushman M, Tsai MY, Heckbert SR, Aleksic N. Prospective study of the G20210A polymorphism in the prothrombin gene, plasma prothrombin concentration, and incidence of venous thromboembolism. Am J Hematol 2002;71:285-290. [PubMed: 12447958]

17. Jun ZJ, Ping T, Lei Y, Li L, Ming SY, Jing W. Prevalence of factor V Leiden and prothrombin G20210A mutations in Chinese patients with deep venous thrombosis and pulmonary embolism. Clin Lab Haematol 2006;28:111-116. [PubMed: 16630215]

18. Dilley A, Austin H, Hooper WC, Lally C, Ribeiro MJ, Wenger NK, et al. Relation of three genetic traits to venous thrombosis in an African-American population. Am J Epidemiol 1998;147:30-35. [PubMed: 9440395]

19. Folsom AR. Update on factor V Leiden association with venous thromboembolism in the LITE Study. Blood 2007;109:1336-1337. [PubMed: 17244690]

20. Dowling NF, Austin H, Dilley A, Whitsett C, Evatt BL, Hooper WC. The epidemiology of venous thromboembolism in Caucasians and African-Americans: the GATE Study. J Thromb Haemost 2003;1:80-87. [PubMed: 12871543]

21. Lutsey PL, Cushman M, Steffen LM, Green D, Barr RG, Herrington D, et al. Plasma hemostatic factors and endothelial markers in four racial/ethnic groups: the MESA study. J Thromb Haemost 2006;4:2629-2635. [PubMed: 17002663]

22. Rosendaal FR. Venous thrombosis: a multicausal disease. Lancet 1999;353:1167-1173. [PubMed: 10209995]

23. Pini M, Spyropoulos AC. Prevention of venous thromboembolism. Semin Thromb Hemost 2006;32:755-766. [PubMed: 17171588]

24. Samama MM. An epidemiologic study of risk factors for deep vein thrombosis in medical outpatients: the Sirius study. Arch Intern Med 2000;160:3415-3420. [PubMed: 11112234] 
25. Abdollahi M, Cushman M, Rosendaal FR. Obesity: risk of venous thrombosis and the interaction with coagulation factor levels and oral contraceptive use. Thromb Haemost 2003;89:493-498. [PubMed: 12624633]

26. Stein PD, Beemath A, Olson RE. Obesity as a risk factor in venous thromboembolism. Am J Med 2005;118:978-980. [PubMed: 16164883]

27. Cushman M, Kuller LH, Prentice R, Rodabough RJ, Psaty BM, Stafford RS, et al. Estrogen plus progestin and risk of venous thrombosis. Jama 2004;292:1573-1580. [PubMed: 15467059]

28. Li C, Ford ES, McGuire LC, Mokdad AH. Increasing Trends in Waist Circumference and Abdominal Obesity among U.S. Adults. Obesity (Silver Spring) 2007;15:216-224. [PubMed: 17228050]

29. Zakai NA, Wright J, Cushman M. Risk factors for venous thrombosis in medical inpatients: validation of a thrombosis risk score. J Thromb Haemost 2004;2:2156-2161. [PubMed: 15613021]

30. Baglin TP, White K, Charles A. Fatal pulmonary embolism in hospitalised medical patients. J Clin Pathol 1997;50:609-610. [PubMed: 9306945]

31. Geerts WH, Pineo GF, Heit JA, Bergqvist D, Lassen MR, Colwell CW, et al. Prevention of venous thromboembolism: the Seventh ACCP Conference on Antithrombotic and Thrombolytic Therapy. Chest 2004;126:338S-400S. [PubMed: 15383478]

32. White RH, Zhou H, Gage BF. Effect of age on the incidence of venous thromboembolism after major surgery. J Thromb Haemost 2004;2:1327-1333. [PubMed: 15304038]

33. Eekhoff EM, Rosendaal FR, Vandenbroucke JP. Minor events and the risk of deep venous thrombosis. Thromb Haemost 2000;83:408-411. [PubMed: 10744145]

34. Piccioli A, Falanga A, Baccaglini U, Marchetti M, Prandoni P. Cancer and venous thromboembolism. Semin Thromb Hemost 2006;32:694-699. [PubMed: 17024596]

35. Blom JW, Vanderschoot JP, Oostindier MJ, Osanto S, van der Meer FJ, Rosendaal FR. Incidence of venous thrombosis in a large cohort of 66,329 cancer patients: results of a record linkage study. J Thromb Haemost 2006;4:529-535. [PubMed: 16460435]

36. Kennedy M, Andreescu AC, Greenblatt MS, Jiang H, Thomas CA, Chassereau L, et al. Factor V Leiden, prothrombin 20210A and the risk of venous thrombosis among cancer patients. Br J Haematol 2005;128:386-388. [PubMed: 15667542]

37. Blom JW, Doggen CJ, Osanto S, Rosendaal FR. Malignancies, prothrombotic mutations, and the risk of venous thrombosis. Jama 2005;293:715-722. [PubMed: 15701913]

38. Cannegieter SC, Doggen CJ, van Houwelingen HC, Rosendaal FR. Travel-Related Venous Thrombosis: Results from a Large Population-Based Case Control Study (MEGA Study). PLoS Med 2006;3

39. Lapostolle F, Surget V, Borron SW, Desmaizieres M, Sordelet D, Lapandry C, et al. Severe pulmonary embolism associated with air travel. N Engl J Med 2001;345:779-783. [PubMed: 11556296]

40. Perez-Rodriguez E, Jimenez D, Diaz G, Perez-Walton I, Luque M, Guillen C, et al. Incidence of air travel-related pulmonary embolism at the Madrid-Barajas airport. Arch Intern Med 2003;163:27662770. [PubMed: 14662631]

41. Crowther MA, Kelton JG. Congenital thrombophilic states associated with venous thrombosis: a qualitative overview and proposed classification system. Ann Intern Med 2003;138:128-134. [PubMed: 12529095]

42. Andreescu ACM, Cushman M, Rosendaal FR. D-dimer as a risk factor for deep vein thrombosis: the Leiden Thrombophilia Study. Thromb Haemost 2002;87:47-51. [PubMed: 11858188]

43. Cushman M, Folsom AR, Wang L, Aleksic N, Rosamond WD, Tracy RP, et al. Fibrin fragment Ddimer and the risk of future venous thrombosis. Blood 2003;101:1243-1248. [PubMed: 12393393]

44. Cattaneo M. Hyperhomocysteinemia and venous thromboembolism. Semin Thromb Hemost 2006;32:716-723. [PubMed: 17024599]

45. den Heijer M, Willems HP, Blom HJ, Gerrits WB, Cattaneo M, Eichinger S, et al. Homocysteine lowering by $\mathrm{B}$ vitamins and the secondary prevention of deep vein thrombosis and pulmonary embolism: A randomized, placebo-controlled, double-blind trial. Blood 2007;109:139-144. [PubMed: 16960155]

46. van Stralen KJ, Blom JW, Doggen CJ, Rosendaal FR. Strenuous sport activities involving the upper extremities increase the risk of venous thrombosis of the arm. J Thromb Haemost 2005;3:2110-2111. [PubMed: 16102123] 
47. Beasley R, Raymond N, Hill S, Nowitz M, Hughes R. eThrombosis: the 21st century variant of venous thromboembolism associated with immobility. Eur Respir J 2003;21:374-376. [PubMed: 12608454]

48. Steffen LM, Folsom AR, Cushman M, Jacobs DR Jr, Rosamond WD. Greater fish, fruit, and vegetable intakes are related to lower incidence of venous thromboembolism: the Longitudinal Investigation of Thromboembolism Etiology. Circulation 2007;115:188-195. [PubMed: 17179018]

49. Prandoni P, Bilora F, Marchiori A, Bernardi E, Petrobelli F, Lensing AW, et al. An association between atherosclerosis and venous thrombosis. N Engl J Med 2003;348:1435-1441. [PubMed: 12686699]

50. van der Hagen PB, Folsom AR, Jenny NS, Heckbert SR, O’Meara ES, Reich LM, et al. Subclinical atherosclerosis and the risk of future venous thrombosis in the Cardiovascular Health Study. J Thromb Haemost 2006;4:1903-1908. [PubMed: 16961598]

51. Reich LM, Folsom AR, Key NS, Boland LL, Heckbert SR, Rosamond WD, et al. Prospective study of subclinical atherosclerosis as a risk factor for venous thromboembolism. J Thromb Haemost 2006;4:1909-1913. [PubMed: 16836659]

52. Stein PD, Kayali F, Olson RE. Analysis of occurrence of venous thromboembolic disease in the four seasons. Am J Cardiol 2004;93:511-513. [PubMed: 14969640]

53. Vandenbroucke JP, Koster T, Briet E, Reitsma PH, Bertina RM, Rosendaal FR. Increased risk of venous thrombosis in oral-contraceptive users who are carriers of factor V Leiden mutation. Lancet 1994;344:1453-1457. [PubMed: 7968118]

54. Rosing J, Middledorp S, Curvers J, Christella M, Thomassen LG, Nicolaes GA, et al. Low-dose oral contraceptives and acquired resistance to activated protein $\mathrm{C}$ : a randomised cross-over study. Lancet 1999;354:2036-2040. [PubMed: 10636369]

55. Prandoni P, Lensing A, Cogo A, Cuppini S, Villalta S, Carta M, et al. The long-term clinical course of acute deep venous thrombosis. Ann Intern Med 1996;125:1-7. [PubMed: 8644983]

56. Heit JA, Mohr DN, Silverstein MD, Petterson TM, O'Fallon WM, Melton LJ. Predictors of recurrence after deep vein thrombosis and pulmonary embolism: a population-based cohort study. Arch Intern Med 2000;160:761-768. [PubMed: 10737275]

57. McRae S, Tran H, Schulman S, Ginsberg J, Kearon C. Effect of patient's sex on risk of recurrent venous thromboembolism: a meta-analysis. Lancet 2006;368:371-378. [PubMed: 16876665]

58. Cushman M, Glynn RJ, Goldhaber SZ, Moll S, Bauer KA, Deitcher S, et al. Hormonal factors and risk of recurrent venous thrombosis: the prevention of recurrent venous thromboembolism trial. J Thromb Haemost 2006;4:2199-2203. [PubMed: 16869933]

59. Agnelli G, Prandoni P, Santamaria MG, Bagatella P, Iorio A, Bazzan M, et al. Three months versus one year of oral anticoagulant therapy for idiopathic deep venous thrombosis. Warfarin Optimal Duration Italian Trial Investigators. N Engl J Med 2001;345:165-169. [PubMed: 11463010]

60. Hron G, Eichinger S, Weltermann A, Minar E, Bialonczyk C, Hirschl M, et al. Family history for venous thromboembolism and the risk for recurrence. Am J Med 2006;119:50-53. [PubMed: 16431184]

61. Ridker PM, Miletich JP, Stampfer MJ, Goldhaber SZ, Lindpainter K, Hennekens CH. Factor V Leiden and risks of recurrent idiopathic venous thromboembolism. Circulation 1995;92:2800-2802. [PubMed: 7586244]

62. Simioni P, Prandoni P, Lensing AW, Scudeller A, Sardella C, Prins MH, et al. The risk of recurrent venous thromboembolism in patients with Arg506--> Gln mutation in the gene for factor V (factor V Leiden). N Engl J Med 1997;336:399-403. [PubMed: 9010145]

63. Kyrle PA, Minar E, Hirschl M, Bialonczyk C, Stain M, Schneider B, et al. High plasma level of factor VIII and the risk of recurrent venous thromboembolism. N Engl J Med 2000;343:457-462. [PubMed: 10950667]

64. Baglin T. Management of thrombophilia: who to screen? Pathophysiol Haemost Thromb 2003;33:401-404. [PubMed: 15692251]

65. Kamphuisen PW, Rosendaal FR. Thrombophilia screening: a matter of debate. Neth J Med 2004;62:180-187. [PubMed: 15460496]

66. Christiansen SC, Cannegieter SC, Koster T, Vandenbroucke JP, Rosendaal FR. Thrombophilia, clinical factors, and recurrent venous thrombotic events. Jama 2005;293:2352-2361. [PubMed: 15900005] 
67. Shrivastava S, Ridker PM, Glynn RJ, Goldhaber SZ, Moll S, Bounameaux H, et al. D-dimer, factor VIII coagulant activity, low-intensity warfarin and the risk of recurrent venous thromboembolism. J Thromb Haemost 2006;4:1208-1214. [PubMed: 16706961]

68. Palareti G, Legnani C, Cosmi B, Guazzaloca G, Pancani C, Coccheri S. Risk of venous thromboembolism recurrence: high negative predictive value of D-dimer performed after oral anticoagulation is stopped. Thromb Haemost 2002;87:7-12. [PubMed: 11848459]

69. Eichinger S, Minar E, Bialonczyk C, Hirschl M, Quehenberger P, Schneider B, et al. D-dimer levels and risk of recurrent venous thromboembolism. Jama 2003;290:1071-1074. [PubMed: 12941680]

70. Palareti G, Cosmi B, Legnani C, Tosetto A, Brusi C, Iorio A, et al. D-dimer testing to determine the duration of anticoagulation therapy. N Engl J Med 2006;355:1780-1789. [PubMed: 17065639]

71. Hron G, Eichinger S, Weltermann A, Quehenberger P, Halbmayer WM, Kyrle PA. Prediction of recurrent venous thromboembolism by the activated partial thromboplastin time. J Thromb Haemost 2006;4:752-756. [PubMed: 16634742]

72. Hron G, Kollars M, Binder BR, Eichinger S, Kyrle PA. Identification of patients at low risk for recurrent venous thromboembolism by measuring thrombin generation. JAMA 2006;296:397-402. [PubMed: 16868297]

73. Kahn SR, Ginsberg JS. The post-thrombotic syndrome: current knowledge, controversies, and directions for future research. Blood Rev 2002;16:155-165. [PubMed: 12163001]

74. Kahn SR, Desmarais S, Ducruet T, Arsenault L, Ginsberg JS. Comparison of the Villalta and Ginsberg clinical scales to diagnose the post-thrombotic syndrome: correlation with patient-reported disease burden and venous valvular reflux. J Thromb Haemost 2006;4:907-908. [PubMed: 16634767]

75. Stain M, Schonauer V, Minar E, Bialonczyk C, Hirschl M, Weltermann A, et al. The post-thrombotic syndrome: risk factors and impact on the course of thrombotic disease. J Thromb Haemost 2005;3:2671-2676. [PubMed: 16359506]

76. Kahn SR, Kearon C, Julian JA, Mackinnon B, Kovacs MJ, Wells P, et al. Predictors of the postthrombotic syndrome during long-term treatment of proximal deep vein thrombosis. $\mathrm{J}$ Thromb Haemost 2005;3:718-723. [PubMed: 15733061]

77. Brandjes DP, Buller HR, Heijboer H, Huisman MV, de Rijk M, Jagt H, et al. Randomised trial of effect of compression stockings in patients with symptomatic proximal-vein thrombosis. Lancet 1997;349:759-762. [PubMed: 9074574]

78. Prandoni P, Lensing AW, Prins MH, Frulla M, Marchiori A, Bernardi E, et al. Below-knee elastic compression stockings to prevent the post-thrombotic syndrome: a randomized, controlled trial. Ann Intern Med 2004;141:249-256. [PubMed: 15313740]

79. Cushman M. Inherited risk factors for venous thrombosis. Hematology Am Soc Hematol Educ Program 2005:452-457. [PubMed: 16304419] 


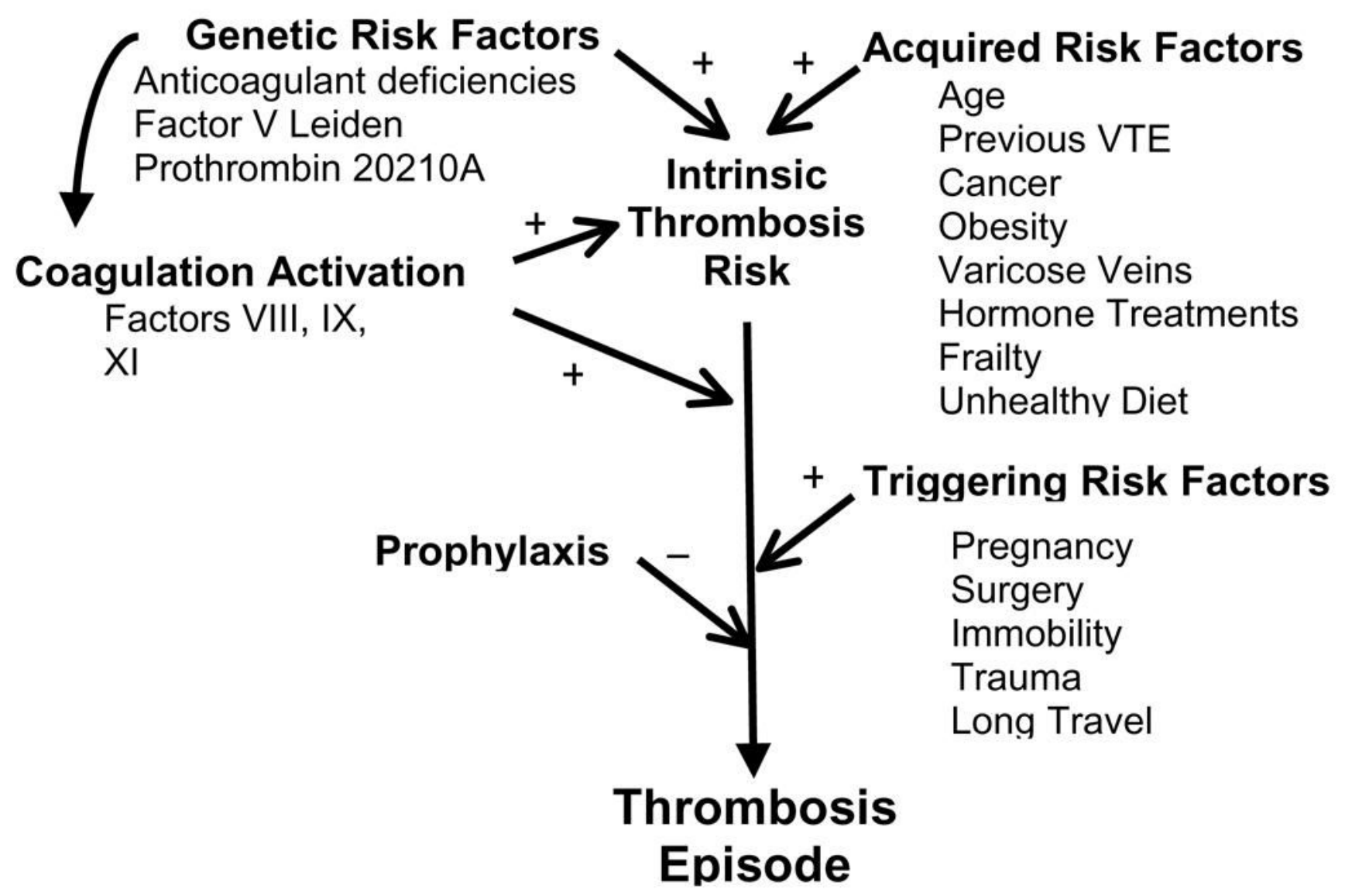

Figure 1.

Conceptual framework for the interaction of risk factors in development of venous thrombosis. Intrinsic thrombosis risk is defined by the combinations of genetic and acquired risk factors, including modulation of coagulation activation by known and unknown determinants. The intrinsic risk is altered by the occurrence of triggering risk factors, which can be balanced in appropriate settings by use of thromboprophylaxis. 


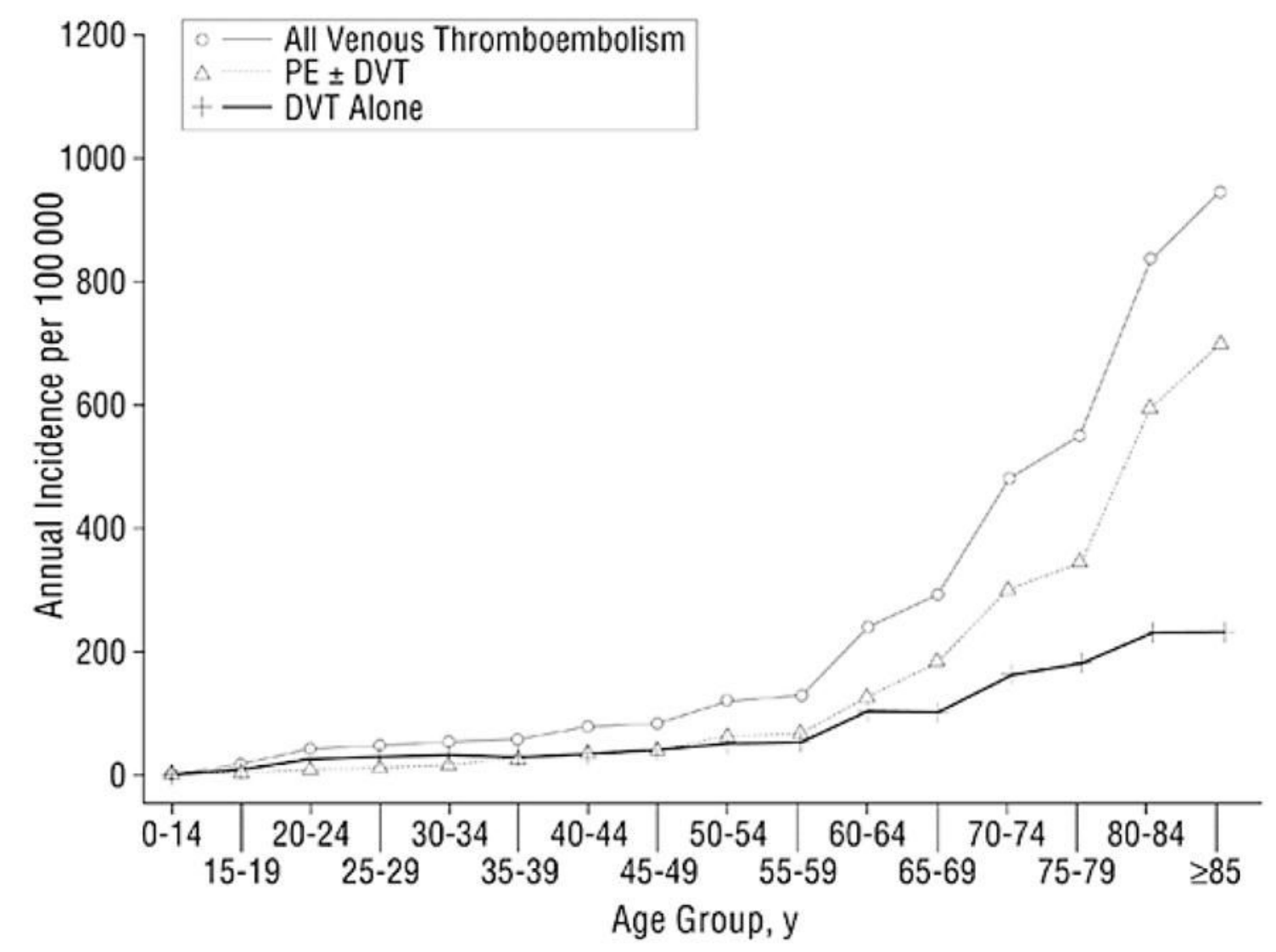

Figure 2.

Annual incidence of all venous thromboembolism, deep vein thrombosis (DVT) alone, and pulmonary embolism (PE) with or without deep vein thrombosis (PE \pm DVT) among residents of Olmsted County, Minnesota, from 1966 to 1990, by age. Reproduced with permission (6). 


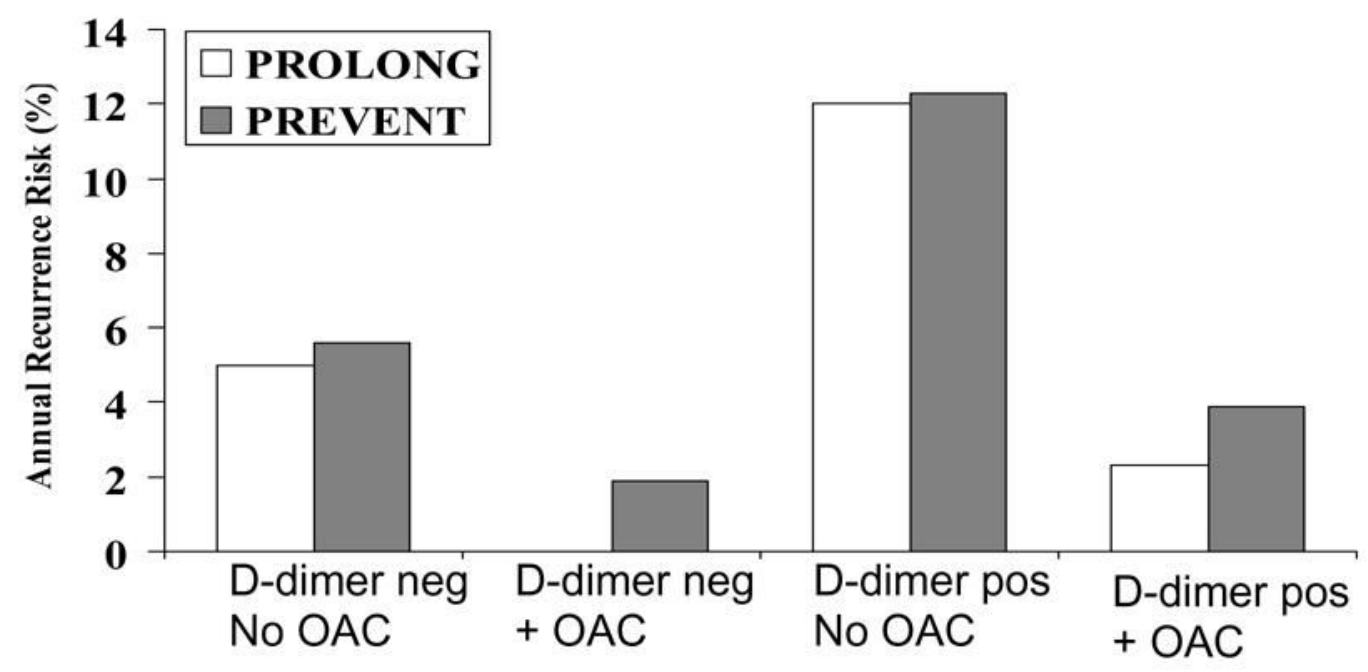

Figure 3.

Results from two clinical trials of D-dimer and the risk of recurrent venous thrombosis among patients with idiopathic first events. The PREVENT study randomized patients to low intensity warfarin therapy (target INR 1.5-2.0) and baseline D-dimer elevation was predictive of the risk of recurrent venous thrombosis, regardless of randomized treatment assignment. The lowest rates of recurrence were in the group with low D-dimer on active treatment (67). The PROLONG study was a management study which observed patients with low D-dimer after completing a course of anticoagulation for first thrombosis, and randomized patients with elevated D-dimer to continued anticoagulation or observation. Similar to PREVENT, those with low D-dimer had a lower recurrence risk, and continued anticoagulation was effective in risk reduction among those with elevated D-dimer (70). Pos, positive; neg, negative; OAC, continued long-term oral anticoagulation with vitamin $\mathrm{K}$ antagonists. 


\section{Risk Factors for Venous Thrombosis}

\section{Table 1}

Older Age

Obesity/Overweight

Personal History of Previous Thrombosis

Family Member with Venous Thrombosis

Surgery

Hospitalization

Cancer

Myeloproliferative Disease

Trauma/Injury, especially of legs/spine

Immobility (bedrest, neurologic, plaster cast)

Varicose Veins

Pregnancy/Puerperium

Postmenopausal Hormone Therapy

Selective Estrogen Receptor Modulating Drugs

Oral Contraceptives

Long Travel

Genetic Factors Affecting Coagulation Balance

Antiphospholipid Syndrome 
Table 2

Relative risk of thrombosis for hemostatic factors comparing the Leiden Thrombophilia Study (LETS) and the Longitudinal Investigation of Thromboembolism Etiology (LITE)

\begin{tabular}{lll}
\hline Risk Factor & LETS & LITE \\
\hline Factor V Leiden & 8.1 & 3.5 \\
Factor V Leiden homozygote & 80 & 24 \\
Prothrombin 20210A & 2.8 & 1.9 \\
Protein C deficiency & 3.1 & 3.4 \\
Elevated factor V & 1.3 & 1.2 \\
Antithrombin deficiency & 5.0 & Not done \\
Elevated factor VIII & 4.8 & 2.6 \\
Elevated factor VII & 0.8 & 2.4 \\
Elevated factor IX & 2.8 & Not done \\
Elevated factor XI & 2.2 & Not done \\
Elevated fibrinogen & 4.0 & 0.9 \\
Elevated D-dimer & 2.5 & 3.1 \\
Elevated homocysteine & 2.5 & 1.5 \\
\end{tabular}

